\title{
Implication of Tityus apiacas (Lourenco, 2002) in scorpion envenomations in the Southern Amazon border, Brazil
}

\author{
Bruna Andressa Jung da Silva ${ }^{[1]}$, Nelson Ferreira Fé ${ }^{[2]}$, André Alexandre dos Santos Gomes ${ }^{[1]}$, \\ Anderson da Silva Souza ${ }^{[1]}$, Jacqueline de Almeida Gonçalves Sachett ${ }^{[1],[2]}$, Hui Wen Fan ${ }^{[3]}$, \\ Gisely Cardoso de Melo ${ }^{[1],[2]}$ and Wuelton Marcelo Monteiro ${ }^{[1],[2]}$
}

[1]. Diretoria de Ensino e Pesquisa, Fundação de Medicina Tropical Dr. Heitor Vieira Dourado, Manaus, AM, Brasil.

[2]. Escola Superior de Ciências da Saúde, Universidade do Estado do Amazonas, Manaus, AM, Brasil.

[3]. Núcleo Estratégico de Venenos e Antivenenos, Instituto Butantan, São Paulo, SP, Brasil.

\begin{abstract}
Herein, four cases of scorpion stings caused by Tityus apiacas recorded from the municipality of Apuí, in the southern region of the Brazilian Amazon, are described. Patients showed systemic clinical manifestations, described as unusual, involuntary, and generalized tingling and numbness, reported by patients as an electric shock sensation, lasting up to 24 hours after the sting. All patients described local pain and sensation, along with other clinical symptoms including local edema and erythema. Systemic manifestations were not life threatening. Antivenom therapy was administered to all patients, who were discharged without complaints.
\end{abstract}

Keywords: Scorpion sting. Tityus apiacas. Envenomation.

\section{INTRODUCTION}

Scorpion stings are a major health problem, notably in the African continent, the Middle East, Southern India, and Latin America, especially in Mexico, Brazil, the Guianas, and in Venezuela. Approximately 2 billion people live in at-risk areas for scorpion envenomation, occurring with a frequency of over 1 million annually worldwide ${ }^{1}$. In Brazil, a total of 727,113 cases of scorpion stings were recorded by the official surveillance system from 2000 to 2015, with an increasing trend, from 12,552 cases in 2000 (7.4_cases/100,000 inhabitants) to 74,598 in 2015 (43.2 cases $/ 100,000$ inhabitants $)^{2}$. Incidence was higher in the northeastern region of the country, with a rate of 76.9 cases $/ 100,000$ inhabitants in 2015 . In the same year, there were 21 and 9.9 cases per 100,000 in the Brazilian Amazon and the State of Amazonas, respectively².

Scorpion stings incidents show an extensive distribution in the Brazilian Amazon and represent a potential health problem for rural communities ${ }^{3}$. In this region, risk of developing severity was significantly higher in children and, interestingly, in stings occurring in the Apuí region of the Southern Amazon ${ }^{3}$. Unfortunately, there is scarce information on the regional

Corresponding author: Dr. Wuelton Marcelo Monteiro.

e-mail: wueltonmm@gmail.com

Received 22 November 2016

Accepted 6 March 2017 scorpion fauna, as well as the differences in their toxicity. Sufficient taxonomical and distribution information is available for thirteen Tityus spp. reported for the State of Amazonas ${ }^{4}$, and the species responsible for human envenomation were identified as Tityus metuendus, Tityus mathieseni, Tityus bastosi, and Tityus silvestris ${ }^{5,6}$. Tityus obscurus has been shown to cause severe stings in the Western region of the State of Pará ${ }^{7}$. Tityus apiacas is a scorpion species recorded in the Southern Amazon ${ }^{8}$, but it has not been associated with envenomation in humans. Thus, the identification of venomous scorpion species is essential to guide future clinical studies and antivenom testing in affected regions, as well as studies of the biological activities of the venoms of Amazon noxious species.

This study aimed to describe four cases of scorpion stings recorded from the municipality of Apuí, in the Southern region of the State of Amazonas, Western Brazilian Amazon.

\section{CASE REPORT}

At the end of 2015, after observing a high clinical severity among scorpion stings occurring in the Southern Amazon, in the Apuí region ${ }^{6}$, the local health secretariat requested for the Fundação de Medicina Tropical Dr. Heitor Vieira Dourado (FMT-HVD), the tertiary reference center for tropical diseases in the State of Amazonas, to identify four scorpion specimens that caused injuries in that municipality. Apuí is located in the Southern Region of the State of Amazonas, Western Brazilian Amazon (Figure 1), and comprises an area of $54,239.9 \mathrm{~km}^{2}$, approximately $408 \mathrm{~km}$ from Manaus, the state capital. 


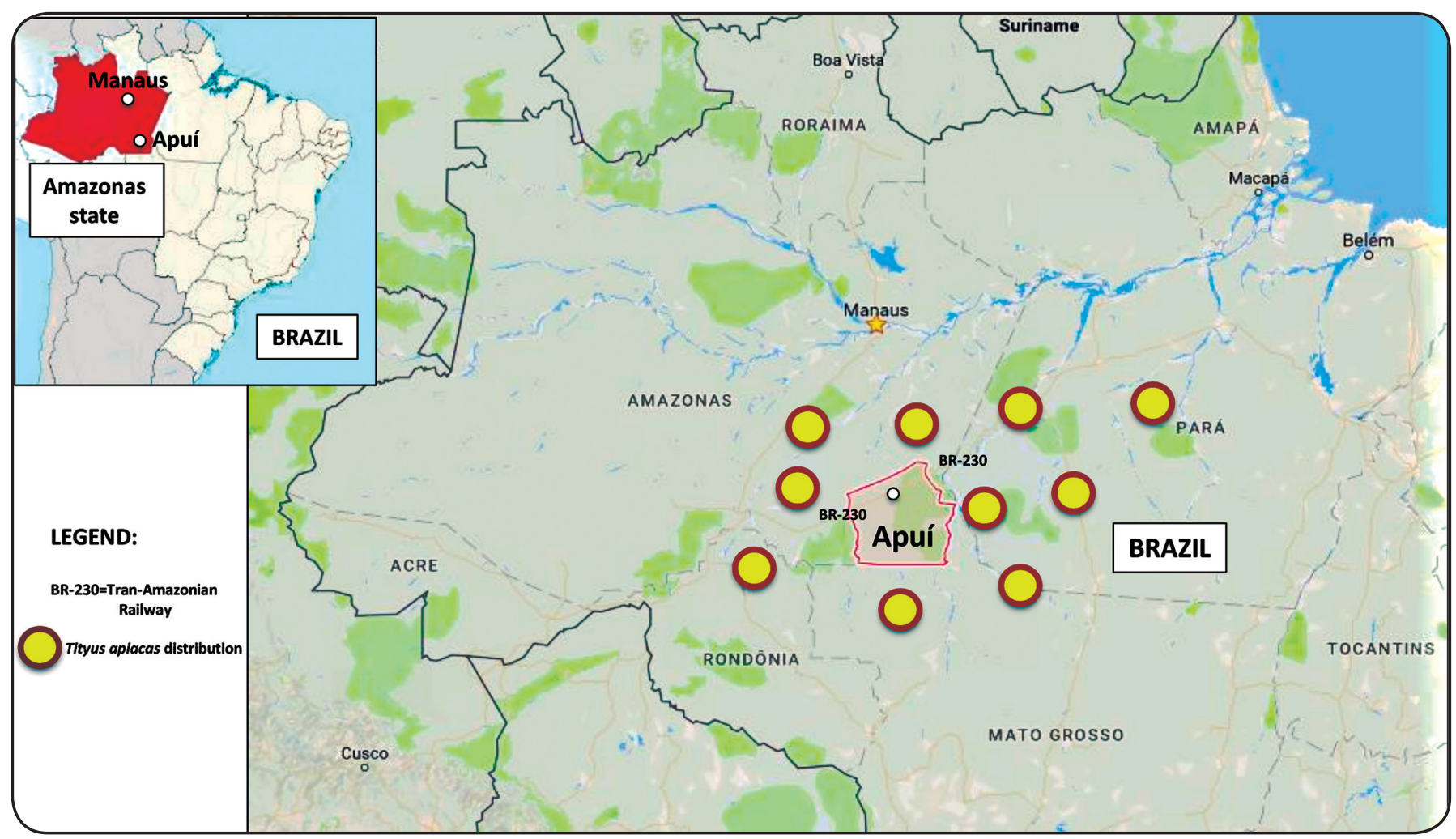

FIGURE 1 - Location of the municipality of Apuí in the Southern Region of the State of Amazonas, Western Brazilian Amazon and of the Tityus apiacas distribution according to Lourenço (8).

The estimated population of the municipality was 20,258 inhabitants in 2014, with $41.2 \%$ living in rural areas. The original vegetation cover is mainly a dense evergreen rain forest. The climate is classified as the equatorial super-humid type, with rainfalls over $2,000 \mathrm{~mm}$ per annum and average annual temperatures between $26^{\circ} \mathrm{C}$ and $28^{\circ} \mathrm{C}$. The main economic activity is related to agriculture (coffee, banana, cassava, beans, soybeans, fruits, vegetables, and sugar cane), cattle breeding, fish farming, and forestry.

Scorpions were collected by the victims and are described in detail in the following section. They presented reddishbrown colorations, especially the older specimens, with some yellowish zones on the sternites. Metasomal segments I to $\mathrm{V}$ were blackish-brown, with 10-8-8-6(8)-5 darker carinae; there was absence of ventral carinae on the metasomal segment IV of male scorpions; telson paler than segment V. There were dentate margins of pedipalp-chela fingers with 16 oblique rows of granules. A strong spinoid subaculear tooth was present, with two dorsal granules. There were pectines with 18 to 20 teeth and the basal middle lamellae dilated in female scorpions. Male pedipalps were longer and more slender than the female pedipalps. Based on these morphological characteristics, and also on previous data regarding spatial distribution of scorpion fauna in the Brazilian Amazon ${ }^{4}$, the specimens collected by the victims were identified as two young female, one of an adult male, and one of an adult female of Tityus apiacas (Figure 2).
Identification was made by one of the authors (Fé NF), in the Department of Entomology of the FMT-HVD, and confirmed by two specialists of the Instituto Butantan (Drs. Denise Maria Candido and Andria de Paula Santos da Silva). Specimens were fixed in ethanol $70 \%$ to be part of the arthropods collection of the FMT-HVD.

Medical records from the Apuí Municipality Hospital were reviewed, with the clinical aspects of the proven T. apiacas cases shown in Table 1. In common, all accidents occurred in rural settings, and most patients were in labor activities. The time elapsed between the scorpion sting and hospital admission was relatively short (less than 3 hours). All patients referred local pain and sensation of electric shock, which started almost immediately after the sting. Other clinical symptoms at admission to the emergency hospital included local edema and erythema. Systemic manifestations were relatively mild and not life threatening; thus, all patients were considered moderately envenomed, according to the Brazilian Ministry of Health guidelines. All remained hemodynamically stable. Antivenom therapy was given to all patients in doses corresponding to moderate envenomation, after pre-medication with IV hydrocortisone and IM promethazine. None presented early reactions to antivenom immunoglobulins. Hematologic and biochemical laboratory tests were not carried out and all patients were discharged without complaints. 


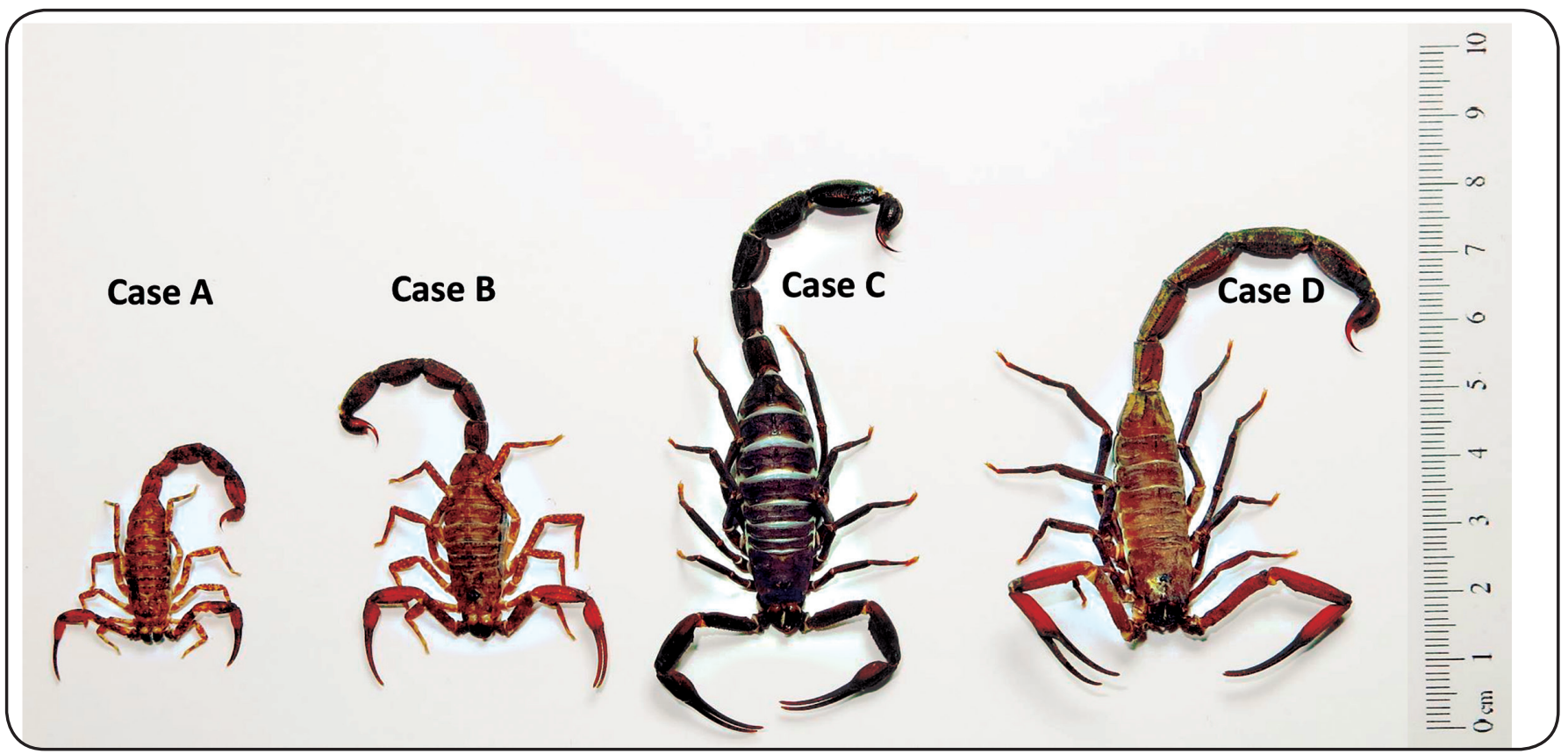

FIGURE 2 - Scorpion specimens of Tityus apiacas collected by the patients identified as sting agents in the study area.

TABLE 1

Demographic and clinical aspects of patients bitten by Tityus apiacas in Southern Amazon.

\begin{tabular}{|c|c|c|c|c|c|c|c|c|c|}
\hline Case & $\begin{array}{l}\text { Age } \\
\text { (years) }\end{array}$ & Gender & $\begin{array}{l}\text { Time from } \\
\text { sting to } \\
\text { hospital } \\
\text { admission }\end{array}$ & Site of sting & $\begin{array}{l}\text { Symptomatology of } \\
\text { envenomation }\end{array}$ & $\begin{array}{l}\text { Antivenom } \\
\text { therapy }\end{array}$ & $\begin{array}{l}\text { Supportive } \\
\text { treatment }\end{array}$ & Outcome & $\begin{array}{c}\text { Identification of the } \\
\text { agent }\end{array}$ \\
\hline A & 55 & Male & $3 \mathrm{~h}$ & Right hand & $\begin{array}{l}\text { Immediate local pain, electric } \\
\text { shock sensation, local } \\
\text { erythema, sweating, tremors }\end{array}$ & 2 vials* & IV dipyrone & $\begin{array}{l}\text { Discharge } 48 \mathrm{~h} \\
\text { after sting }\end{array}$ & $\begin{array}{l}\text { Tityus apiacas, } \\
\text { 42mm young female } \\
\text { (Figure } \mathbf{2 A} \text { ) }\end{array}$ \\
\hline $\mathrm{C}$ & 48 & Female & $3 \mathrm{~h}$ & $\begin{array}{l}\text { Finger of right } \\
\text { hand }\end{array}$ & $\begin{array}{l}\text { Immediate local pain, electric } \\
\text { shock sensation, local edema } \\
\text { and erythema, tremors }\end{array}$ & 2 vials $^{*}$ & Not referred & $\begin{array}{l}\text { Discharge } 48 \mathrm{~h} \\
\text { after sting }\end{array}$ & $\begin{array}{l}\text { Tityus apiacas, } \\
\text { 85mm adult male } \\
\text { (Figure 2C) }\end{array}$ \\
\hline
\end{tabular}

*Tityus antivenom. **Loxosceles and Phoneutria spiders and the Tityus scorpion antivenom.

\section{Ethical considerations}

This study was approved by the Ethics Review Board of the Fundação de Medicina Tropical Dr. Heitor Vieira Dourado (approval number 872.520/2014).

\section{DISCUSSION}

In the present study, we report four cases of human envenomation caused by T. apiacas in the Amazon region.
The most frequent species involved in human stings are referred as being T. obscurus, Tityus silvestris, and T. metuendus ${ }^{5,7}$, probably owing to their large geographical distribution in the Amazon basin; whereas Tityus apiacas Lourenço, 2002, has a Southern distribution in Amazonia, South of the Rio Solimões/ Amazonas in the States of Amazonas, Mato Grosso and Pará, Brazil. These species belong to the group Tityus asthenes, and it is closely related to T. obscurus and Tityus dinizi, thus potentially leading to a misidentification between $T$. apiacas and 
T. obscurus. Both species are usually dark-colored, and large, from 75 to $100 \mathrm{~mm}$ in total length when adult ${ }^{8}$.

Clinical manifestations in our scorpion-envenomed patients are similar as those described for some moderate T. obscurus envenomations ${ }^{7}$ and diverse from those reported in other Brazilian regions, specifically Tityus serrulatus scorpion stings ${ }^{9}$, which have a distinct spectrum of symptomatology when compared with the other scorpions in the Amazon. Patients stung by T. apiacas showed systemic clinical manifestations, described as unusual, involuntary, and generalized tingling and numbness, affecting mainly the trunk and both legs that prevented walking or holding objects. Reported by patients as an electric shock sensation, this set of symptoms lasted up to 24 hours after the sting. However, other neurological manifestations described in T. obscurus envenomation, such as myoclonia, dysmetria, dysarthria, and ataxia ${ }^{7}$ were not recorded, although specific neurological examination were not performed and therefore these neurological issues could be present to some extent. This may be owing to differences in venom composition. Oddly, there are no studies on the composition and mechanism of action of $T$. apiacas venom.

The rapid onset of the clinical manifestations as herein reported corroborates experimental studies of the pharmacokinetics of scorpion venom injection, demonstrating rapid venom absorption ${ }^{10}$. These findings indicate the importance in the recognition of risk groups and early intervention.

To better understand the effects of T. apiacas and other Amazonian scorpion venoms, studies should be carried out to evaluate the Tityus antivenom for clinical use in the Amazon. In the process of this antivenom production, horses are immunized by antigens from $T$. serrulatus venom, thus purifying specific antibodies from the hyperimmune plasma ${ }^{11}$. For the treatment of systemic scorpion envenomation, two types of antivenoms are available in Brazil and are equally distributed throughout the country: Tityus antivenom and Loxosceles, Phoneutria, and Tityus antivenom. Both products have the same in vivo potency specification and use the same production process involving T. serrulatus venom as an antigen to immunize horses. Therefore, it is fundamental to assess the potential differences in toxin antigenic cross-reactivity between Amazonian species and the prevalent of antivenom produced in Brazil, as well as to establish the ideal therapeutic approach for these scorpion stings. Nevertheless, it is always important to consider symptomatic treatment to treat painful symptoms, and to prevent systemic complications. As used in the four cases, oral or parenteral analgesics are important since pain is frequent and sometimes intense. Local anesthesia should not be used, since local injection of anesthetics could exacerbate muscle spasms, responsible for the electric shock sensation. Our data are not conclusive regarding the efficacy of antivenom in reversing systemic envenomation. Differences in the venom composition and the spectrum of envenomation may also hamper comparisons with the outcome of patients stung by $T$. apiacas and T. serrulatus. Nevertheless, it is noticeable that all patients described a consistent tingling and numbness that subsided only after 24 hours of medical observation, as in T. obscurus envenomation ${ }^{7}$. However, antivenom reverse scorpion envenomation lasted up to two hours after specific therapy in $T$. serrulatus scorpion stings ${ }^{12}$. In vivo experiments and randomized clinical trials should assess if the commonly available antivenom in Brazil can effectively resolve the clinical neurotoxic manifestations associated with envenomation by scorpions of the Amazon.

\section{Acknowledgments}

To Dr. Rosangela Motter Detoni and Valdete Luiz Angélico, from the Apuí Health Secretariat, for the permits to access the data. To Dr. Pedro Pardal, for their kind comments. To Drs. Denise Maria Candido and Andria de Paula Santos da Silva (Butantan Institute) for the confirmation of the identification of the scorpions.

\section{Conflict of interest}

The authors declare that have no conflicts of interest.

\section{REFERENCES}

1. World Health Organization. Rabies and envenomings: a neglected public health issue: report of a Consultative Meeting [Internet]. Geneva: World Health Organization; 2007 [updated 2016 June 15]. Available from: http://www.who.int/bloodproducts/snake antivenoms/rabies_envenomings/en/

2. Ministério da Saúde. Animais peçonhentos. Escorpiões. Situação epidemiológica [Internet]. Brasília: Ministério da Saúde; 2015 [updated 2016 June 15]. Available from: http://portalsaude.saude.gov.br/index. php/o-ministerio/principal/leia-mais-o-ministerio/1019-secretariasvs/vigilancia-de-a-a-z/animais-peconhentos-escorpioes/12-animaispeconhentos-escorpioes/13692-situacao-epidemiologica-dados.

3. Queiroz AM, Sampaio VS, Mendonça I, Fé NF, Sachett J, Ferreira LCL, et al. Severity of Scorpion Stings in the Western Brazilian Amazon: a case-control study. PLoS One. 2015;10:e0128819.

4. Lourenço WR. Scorpions of Brazil. Les Éditions de L'If; 2002. $308 \mathrm{p}$.

5. Costa CLSO, Fé NF, Sampaio I, Tadei WP. A profile of scorpionism, including the species of Scorpions involved, in the State of Amazonas, Brazil. Rev Soc Bras Med Trop. 2016;49(3):376-9.

6. Monteiro WM, Oliveira SS, Pivoto G, Alves EC, Sachett JAG, Alexandre CN, et al. Scorpion envenoming caused by Tityus cf. silvestris evolving with severe muscle spasms in the Brazilian Amazon. Toxicon. 2016;119:266-9.

7. Pardal PPO, Ishikawa EAY, Vieira JLF, Coelho JS, Dórea RCC, Abati PAM, et al. Clinical aspects of envenomation caused by Tityus obscurus (Gervais, 1843) in two distinct regions of Pará state, Brazilian Amazon basin: a prospective case series. J Venom Anim Toxins Trop Dis. 2014;20:2-7.

8. Lourenço WR. Nouvelles additions à la faune de scorpions néotropicaux (Arachnida). Rev Suisse Zool. 2002;109:127-41.

9. Bucaretchi F, Fernandes LCR, Fernandes CB, Branco MM, Prado CC, Vieira RJ, et al. Clinical consequences of Tityus bahiensis and Tityus serrulatus scorpion stings int the region of Campinas, Southeastern Brazil. Toxicon. 2014;89:17-25.

10. Revelo MP, Bambirra EA, Ferreira AP, Diniz CR, Chávez-Olórtegui C. Body distribution of Tityus serrulatus scorpion venom in mice and effects of scorpion antivenom. Toxicon. 1996;34:1119-25.

11. Carmo AO, Chatzaki M, Horta CCR, Magalhães BF, OliveiraMendes BBR, Chávez-Olórtegui C, et al. Evolution of alternative methodologies of scorpion antivenoms production. Toxicon. 2015;97:64-74.

12. Resende NA, Dias MB, Campolina D, Chaves-Olortegui C, Diniz $\mathrm{CR}$, Amaral CF. Efficacy of antivenom therapy for neutralizing circulating venom antigens in patients stung by Tityus serrulatus scorpions. Am J Trop Med Hyg. 1995;52:277-80. 